\title{
Review of the Evidence on Diagnosis of Deep Venous Thrombosis and Pulmonary Embolism
}

\author{
Jodi B. Segal, MD, MPH \\ Jobn Eng, $M D^{2}$ \\ Leonardo J. Tamariz, $M D, M P H^{3}$ \\ Eric B. Bass, MD, $M P H^{1,4}$ \\ 'Johns Hopkins University School of Medi- \\ cine, Department of Medicine, Baltimore, Md \\ ${ }^{2}$ Johns Hopkins University School of \\ Medicine, Department of Radiology, \\ Baltimore, Md \\ ${ }^{3}$ University of Miami School of Medicine, \\ Department of Medicine, Miami, Fla \\ ${ }^{4}$ Johns Hopkins University School of \\ Medicine, Evidence-Based Practice Center, \\ Baltimore, Md
}

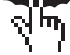

MORE ONLINE

www.annfammed.org

\begin{abstract}
PURPOSE This review summarizes the evidence regarding the efficacy of techniques for diagnosis of deep venous thrombosis (DVT) and pulmonary embolism.

METHODS We searched for studies using MEDLINE, MICROMEDEX, the Cochrane Controlled Trials Register, and the Cochrane Database of Systematic Reviews through June 2006. We reviewed randomized controlled trials, systematic reviews of trials, and observational studies if no trials were available. Paired reviewers assessed the quality of each included article and abstracted the data into summary tables. Heterogeneity in study designs precluded mathematical combination of the results of the primary literature.
\end{abstract}

RESULTS Our review found 22 relevant systematic reviews and 36 primary studies. The evidence strongly supports the use of clinical prediction rules, particularly the Wells model, for establishing the pretest probability of DVT or pulmonary embolism in a patient before ordering more definitive testing. Fifteen studies support that when a D-dimer assay is negative and a clinical prediction rule suggests a low probability of DVT or pulmonary embolism, the negative predictive value is high enough to justify foregoing imaging studies in many patients. The evidence in 5 systematic reviews regarding the use of D-dimer, in isolation, is strong and demonstrates sensitivities of the enzyme-linked immunosorbent assay (ELISA) and quantitative rapid ELISA, pooled across studies, of approximately 95\%. Eight systematic reviews found that the sensitivity and specificity of ultrasonography for diagnosis of DVT vary by vein; ultrasonography performs best for diagnosis of symptomatic, proximal vein thrombosis, with pooled sensitivities of $89 \%$ to $96 \%$. The sensitivity of single-detector helical computed tomography for diagnosis of pulmonary embolism varied widely across studies and was below $90 \%$ in 4 of 9 studies; more studies are needed to determine the sensitivity of multidetector scanners.

CONCLUSIONS While the strength of the evidence varies across questions, it is generally strong.

Ann Fam Med 2007;5:63-73. DOI: 10.1370/afm.648.

\section{INTRODUCTION}

$\mathrm{V}$ enous thromboembolism (VTE), including deep venous thrombosis (DVT) and pulmonary embolism, afflicts an estimated 71 per 100,000 persons yearly. ${ }^{1}$ Approximately one third of patients with VTE have a pulmonary embolism, whereas two thirds have DVT alone. ${ }^{2}$ The incidence rate of isolated deep venous thrombosis, from 9 populationbased studies, is around 50 per 100,000 person-years. ${ }^{3}$ A community-wide study in Massachusetts estimated an incidence of pulmonary embolism, with or without DVT, of 23 per 100,000 and an incidence rate of DVT alone of 48 per 100,000 person-years. ${ }^{4}$ The incidence rate of pulmonary embolism is challenging to quantify, however, as it is often not diagnosed without autopsy. Possibly up to $30 \%$ of patients with DVT develop symp- 
tomatic pulmonary embolism, and another $40 \%$ have asymptomatic pulmonary embolism, which can be found with radiological tests. ${ }^{5}$ Pulmonary embolism dramatically reduces short- and long-term survival among patients with VTE. ${ }^{6}$ Despite anticoagulant therapy, VTE recurs frequently in the first few months after the initial event. ${ }^{7}$ Expedient diagnosis is crucial for prompt initiation of treatment, which improves patient outcomes. ${ }^{8}$

All diagnostic tests involve a trade-off between sensitivity and specificity. Highly sensitive tests reduce harm by limiting false-negative results and allowing a patient to promptly begin treatment. Highly specific tests reduce harm by limiting unnecessary and perhaps risky confirmatory tests, as well as incorrect treatment. Diagnosis of VTE requires a test with high sensitivity, as a missed DVT diagnosis can result in a deadly pulmonary embolus or, at a minimum, posthrombotic syndrome in the leg. In contrast, a test with low specificity cannot be tolerated, as a false-positive result commits a patient to anticoagulation with its attendant risks.

This review summarizes the evidence available during formulation of the guidelines for diagnosis of VTE from the Academy of Family Physicians (AAFP) and American College of Physicians (ACP). The foundation of this background article was a systematic review of the evidence for both the diagnosis and management of VTE. ${ }^{9}$ For this review, we focused on the evidence for diagnostic tests for identifying VTE that are currently in common use by clinicians and for which the evidence to support their use is not known with certainty. The purpose of this article is not to make recommendations based on the evidence; this is the goal of the accompanying guideline. ${ }^{10}$ The questions addressed in this review are as follows: (1) Are clinical prediction rules valuable for diagnosing DVT or pulmonary embolism, and does addition of the D-dimer assay improve the test characteristics of clinical prediction rules? (2) What are the test characteristics of D-dimer measurement alone when used for diagnosis or exclusion of DVT or pulmonary embolism, and how does choice of assay affect the test characteristics? (3) What are the test characteristics of ultrasonography for diagnosis of deep venous thrombosis, including calf vein thrombosis and upper-extremity thrombosis? (4) What are the test characteristics of computed axial tomography (CT) for diagnosis of pulmonary embolism?

\section{METHODS}

A full description of the methods used in the systematic review can be found in a detailed evidence report and in 2 related articles. ${ }^{9,11,12}$ A brief description of these methods and additional methods are below.

\section{Literature Identification}

We searched literature-indexing systems to identify the articles relevant to our review, including MEDLINE, EMBASE, the Cochrane Controlled Trials Register, and the Cochrane Database of Systematic Reviews. To ensure identification of all relevant articles, we examined the reference lists from material identified through the electronic searching and from discussion with experts, and reviewed the tables of contents of recent issues of the most relevant journals. For our prior evidence report, we searched for citations from the above sources through March 2002. For the current review, we initially extended the search through November 2004. As imaging technology rapidly evolves, however,we extended the search for evidence regarding $\mathrm{CT}$ scanning and ultrasonography through June 2006.

Two members of the study team independently reviewed the titles and abstracts identified by the search to exclude those that did not meet the following eligibility criteria. For primary literature, the article described in the abstract must have been in English, addressed one of the key questions, not studied VTE prophylaxis only, included original human data, and not been a single-patient case report. For our review of relevant systematic reviews, the above criteria applied except the article must have included a systematic review, meta-analysis, or cost-effectiveness analysis. Additionally, data published only in abstract form were excluded. Each individual question had additional inclusion and exclusion criteria as described below. If both reviewers agreed, the abstract was included, and the full article was retrieved for review.

\section{Article Review Process and Data Abstraction}

In the previous systematic review, ${ }^{13} 13$ systematic reviews were relevant to our questions about diagnosis of VTE, and 27 primary studies were relevant to these questions. In our additional searching, we identified another 18 recent studies relevant to these questions.

Paired reviewers abstracted data. Evidence tables were populated with the data, and an assessment was made of the quality of the article using validated instruments, where available.

\section{Statistical Analysis}

Qualitative heterogeneity between the studies in their designs and outcomes precluded pooling the study results. Confidence intervals surrounding sensitivities and specificities were calculated assuming a binomial distribution. For the clinical prediction rule question, ROC curves were fitted using maximum likelihood estimation methods assuming a binormal distribution. The area under the curve was measured using ROCFIT. ${ }^{14}$ 


\section{Grading the Evidence}

Evidence was graded by 2 authors according to the Strength of Recommendation Taxonomy (SORT) developed by a consortium of editors of US family medicine and primary care journals. ${ }^{15}$ Level 1 evidence indicates good-quality patient-oriented evidence, level 2 indicates limited-quality patient-oriented evidence, and level 3 indicates when evidence does not meet the criteria for levels 1 or 2 .

\section{Role of Funding Sources}

The initial systematic review was funded through a contract with the Agency for Healthcare Research and Quality. Additionally, the ACP offered a small honorarium for updating the review. Members of the ACP/ AAFP guidelines committee for management of VTE reviewed drafts of this article.

\section{DATA SYNTHESIS}

\section{Clinical Prediction Rules}

Are clinical prediction rules valuable for diagnosing DVT or pulmonary embolism? Does addition of D-dimer improve test characteristics of clinical prediction rules?

A clinical prediction rule is a scoring system that calculates the pretest probability of a disease (here, DVT or pulmonary embolism) from a clinical assessment of risk factors and physical findings, either as a scalar probability or as a category (high, medium, or low). Patients are classified as having a high, moderate, or low clinical probability, and this classification is compared with the reference standard, which is positive or negative for disease. The sensitivities and specificities of the rule (at each cutoff) reflect how correctly the rule predicts the presence or absence of disease. We identified 19 studies that evaluated clinical prediction rules for the diagnosis of DVT, ${ }^{16-34}$ and 8 studies evaluating clinical prediction rules for the diagnosis of pulmonary embolism, ${ }^{35-42}$ although common patients were reported in 3 studies. $^{40-42}$ (Supplemental Appendix 1, available online at

http://www.annfammed.org/cgi/content/full/5/1/63/DC1). The quality of the studies was fairly high, because all patients had an appropriate reference standard, the study sample was well described, and there was no verification bias. Most studies, however, did not have 2 independent observers applying the prediction rules and lacked blinded and independent interpretation of the reference standard. In the studies evaluating DVT predic- tion, 7,418 patients were studied. The mean age of the patients across studies ranged from 54 to 68 years. Risk factors for VTE among the studied patients were inconsistently reported. The Wells prediction rule was most frequently evaluated in these studies (Table 1); only 2 studies validated other prediction rules, ${ }^{27,28}$ and 1 study compared the Wells rule with other prediction rules. ${ }^{24}$

In the 15 studies that evaluated the Wells DVT prediction rule, patients whose test scores put them in the highest strata of pretest probability had a prevalence of DVT, across studies, ranging from $17 \%$ to $85 \%$. Those with a moderate pretest probability had a prevalence of $0 \%$ to $38 \%$, and patients with the lowest pretest probability had a prevalence of $0 \%$ to $13 \%$.

We calculated the area under the ROC curve as an overall summary of the discriminatory power of each rule. Because the prediction rule cutoffs are set by the authors of the rules, users are not expected to use their own cutoffs and operate at different places on the curve. An area under the curve of 1.0 means that the test discriminates perfectly between patients with and without the disease of interest; an area of 0.50 means that the test cannot discriminate between patients with and without the disease. The area under the ROC curve for these studies ranged from 0.72 to 0.90 , suggesting modest discrimination between patients with DVT and without. We did not create summary ROC curves because the studies were too different in their populations to allow pooling on one curve.

The clinical prediction rules for the diagnosis of pulmonary embolism were evaluated in 4,693 patients. The mean age of the patients was 51 to 64 years, and men accounted for the majority of the participants.

\section{Table 1. Wells Prediction Rule for Deep Venous Thrombosis: Clinical Evaluation Table for Predicting Pretest Probability of Deep Vein Thrombosis}

\begin{tabular}{|c|c|}
\hline Clinical Characteristic & Score \\
\hline Active cancer (treatment ongoing, within previous 6 months or palliative) & 1 \\
\hline Paralysis, paresis, or recent plaster immobilization of the lower extremities & 1 \\
\hline $\begin{array}{l}\text { Recently bedridden }>3 \text { days or major surgery within } 12 \text { weeks requiring } \\
\text { general or regional anesthesia }\end{array}$ & 1 \\
\hline Localized tenderness along the distribution of the deep venous system & 1 \\
\hline Entire leg swollen & 1 \\
\hline $\begin{array}{l}\text { Calf swelling } 3 \mathrm{~cm} \text { larger than asymptomatic side (measured } 10 \mathrm{~cm} \\
\text { below tibial tuberosity) }\end{array}$ & 1 \\
\hline Pitting edema confined to the symptomatic leg & 1 \\
\hline Collateral superficial veins (nonvaricose) & 1 \\
\hline Alternative diagnosis at least as likely as deep venous thrombosis & -2 \\
\hline \multicolumn{2}{|c|}{$\begin{array}{l}\text { Note: A score of } 3 \text { or higher indicates a high probability of deep vein thrombosis; } 1 \text { or 2, a mod- } \\
\text { erate probability; and } 0 \text { or lower, a low probability. In patients with symptoms in both legs, the } \\
\text { more symptomatic leg is used. }\end{array}$} \\
\hline $\begin{array}{l}\text { Reprinted from The Lancet, Vol 350, Wells PS, Anderson DR, Bormanis J, et al. Value of } \\
\text { of pretest probability of deep-vein thrombosis in clinical management, pp 1795-1798, } \\
\text { 2002, with permission from Elsevier. }\end{array}$ & $\begin{array}{l}\text { essment } \\
\text { yright }\end{array}$ \\
\hline
\end{tabular}


In these 8 studies, several different clinical prediction rules were evaluated. In the 3 studies in which the Wells prediction rule was evaluated, the prevalence of pulmonary embolism for those patients in the high pretest probability stratum ranged from $38 \%$ to $78 \%$. Those in the moderate pretest probability stratum had a prevalence of pulmonary embolism that ranged from $16 \%$ to $28 \%$, and those in the low pretest probability stratum had a prevalence of pulmonary embolism that ranged from $1 \%$ to $3 \% \cdot 35,37,38$ In the 2 studies that evaluated the Geneva rule (Table 2), the prevalence of pulmonary embolism in the high pretest probability stratum was $77 \%$ to $85 \% .{ }^{41,42}$ Those in the moderate pretest probability stratum had a prevalence of $34 \%$ to $35 \%$, and those in the low pretest probability stratum had a prevalence of $7 \%$. These 2 studies included common patients. The study that compared both prediction rules reported similar results. ${ }^{40}$ The area under the ROC curve for the Wells pulmonary embolism prediction rule ranged from 0.52 to 0.88 and the area for the Geneva pulmonary embolism prediction rule ranged from 0.69 to 0.84 .

We also identified 15 studies that combined a clinical prediction rule with a D-dimer assay. All but one used the Wells prediction rule. ${ }^{42}$ The studies used assorted algorithms to reclassify the patients as to their probabilities of having VTE using the results from D-dimer testing after applying the clinical prediction rule. The area under the curve for these 11 studies ranged from 0.81 to 0.91 . These results support the recent findings of a systematic review in which patients with a negative $\mathrm{D}$-dimer and low pretest probability had a 3-month incidence of objectively-documented venous thromboembolism of just $0.5 \%$ compared with those individuals with a negative D-dimer and moderate or high pretest probabilities, who had incidences of DVT of $3.5 \%$ and $21.4 \%$, respectively. ${ }^{43}$

These results provide strong evidence to support the use of a clinical prediction rule for establishing the pretest probability of disease in a patient before more

* References 19, 22, 23, 25, 26, 28-32, 34, 37, 38, 41, 42. definitive testing. Additionally, the evidence shows that use of a D-dimer assay with a clinical prediction rule has a very high negative predictive value. This is level 1 evidence.

\section{D-dimer Measurement}

What are the test characteristics of D-dimer measurement for diagnosis or exclusion of DVT or pulmonary embolism, and bow does choice of assay affect test characteristics?

Several high-quality systematic reviews have recently evaluated the use of D-dimer testing for diagnosis or exclusion of VTE. We reviewed 5 systematic reviews, published between 1996 and 2004, that addressed the use of a D-dimer assay in isolation for diagnosis or exclusion of VTE (ie, without clinical data or other diagnostic testing) ${ }^{44-48}$ (Supplemental Appendix 2, available online at http://www.annfammed. org/cgi/content/full/5/1/63/DC1). We excluded one meta-analysis that had been in our previous review because it focused exclusively on patients who had normal lower extremity ultrasound findings. ${ }^{49}$ The earliest review ${ }^{44}$ was later updated by the same group, so we focus here on the later study. ${ }^{47}$

Brown and colleagues published 2 high-quality meta-analyses addressing the use of a D-dimer assay in the exclusion of pulmonary embolism. ${ }^{45,46}$ One of the systematic reviews included 11 studies evaluating 
enzyme-linked immunosorbent assays (ELISA) in 2,126 patients, ${ }^{46}$ and the other included 9 studies evaluating latex turbidimetric assays in 1,901patients. ${ }^{45}$ The methods in the 2 meta-analyses were similar, with inclusion of only studies that used defined reference standards to reduce reference standard bias. The authors pooled the results using random effects models, and plotted summary ROC curves. For both analyses, the authors used the test results as reported in the primary literature at a D-dimer cutoff of $500 \mathrm{ng} / \mathrm{mL}$. The pooled sensitivity of the ELISA assays for diagnosing pulmonary embolism was 95\% (95\% confidence interval [CI], 90\%-98\%) and the specificity was $45 \%$ (95\% CI, 38\%-52\%). Latex turbidimetric assay results were similar with a sensitivity of $93 \%$ and specificity of $51 \%$. The authors' ability to comment on subgroups was limited by having few studies. The D-dimer ELISA had higher specificity in patients without comorbidity than patients with comorbidity, but was less sensitive in that subgroup. The specificity of the test was lower in the elderly and lower in patients with symptoms for longer than 3 days. The authors concluded that both the ELISA and latex turbidimetric assays are highly sensitive and therefore may be clinically useful in excluding disease in patients with a low to moderate clinical probability of pulmonary embolism. The difference in performance between the 2 tests was thought to be minimal, although the difference in performance was not formally tested.

Heim et al evaluated use of a D-dimer assay in patients with symptoms of lower extremity DVT. ${ }^{47}$ They included 23 studies with 3,985 patients. Fourteen of these studies enrolled outpatients exclusively. The diagnostic odds ratio was used as the metric to compare the results of one assay against another, but there was no pooling of sensitivities and specificities within the different types of assays as a result of heterogeneity between the studies. The authors concluded that there was not clearly an optimal assay type among the 6 groups of assays evaluated. These authors noted that in many of the studies the sensitivity of the assay was less than $90 \%$, making it insufficiently sensitive to "rule out" a diagnosis of DVT. The performance of the assays was affected by the prevalence of DVT in the population (a higher prevalence was thought to correspond to a sicker population with more comorbidity) and the choice of reference test. The assays performed best when venography was the reference test, and they were more sensitive for diagnosing thrombus above the knee than for diagnosing calf-vein thrombosis.

Stein et al published a careful meta-analysis of 78 studies of D-dimer assays used for either DVT or pulmonary embolism diagnosis. ${ }^{48}$ These authors included all types of D-dimer assays, grouped into 7 categories, and included studies using a mixture of reference tests.
The authors pooled the sensitivities and specificities by assay type, and evaluated how these test characteristics varied by several explanatory variables using a regression model. For DVT diagnosis, the pooled sensitivities of the assays was highest for the ELISA and quantitative rapid ELISA assays, with sensitivities of 95\% (95\% CI, 91\%-9\%) and 96\% (95\% CI, 90\%-100\%), respectively. For pulmonary embolism diagnosis, the pooled sensitivities of the assays was again highest for the ELISA and quantitative rapid ELISA assays, with sensitivities of $96 \%$ (95\% CI, 88\%-100\%) and 97\% (95\% CI, 87\%-100\%), respectively. Pooled specificities were in the $40 \%$ to $50 \%$ range for these assays. The authors concluded that the negative predictive values for ELISA assays, particularly the quantitative rapid ELISA assays, are sufficiently high that these assays should be able to stand alone in excluding a diagnosis of DVT or pulmonary embolism.

The evidence supports the use of a negative Ddimer assay to exclude VTE, although test performance varies importantly by population and type of assay. This is level 1 evidence.

\section{Ultrasonography}

What are the test characteristics of ultrasonograpby for diagnosis of DVT, including calf vein thrombosis and upper-extremity thrombosis?

We identified 8 systematic reviews that summarized the accuracy of ultrasonography for the diagnosis of DVT (Table 3) ${ }^{50-57}$ (Supplemental Appendix 3, available online at http://www.annfammed. org/cgi/content/full/5/1/63/DC1). All reviews defined contrast venography as the reference standard required for study inclusion, and included studies using duplex ultrasonography, with or without color Doppler, or real-time B-mode ultrasonography. Several reviews stratified results by the type of ultrasonography. ${ }^{52,56}$ The reviews included studies of symptomatic patients, ${ }^{52,56}$ asymptomatic patients, ${ }^{53,57}$ or both. ${ }^{54}$ They included studies to detect thrombosis of the proximal veins, ${ }^{50,52-54}$ distal veins, ${ }^{55}$ or both. ${ }^{51,57}$ One review focused only on detecting thrombosis of the upper extremity veins ${ }^{56}$ The overall quality of these reviews was variable, with generally poor description of the search strategies for identifying articles for inclusion. There were 122 primary articles in these reviews, with little overlap in the included studies across reviews. Only 4 studies appeared in 4 or more reviews.

For the diagnosis of symptomatic thrombosis in the proximal veins of the lower extremity, the reviews reported summary sensitivities of $89 \%$ to $96 \%$ and summary specificities of $94 \%$ to $99 \%$ (Table 3). For detection of thrombi in proximal veins in asymptomatic patients, the reviews suggested that high specific- 


\begin{tabular}{|c|c|c|c|c|c|c|}
\hline Author, Year & $\begin{array}{c}\text { Clinical } \\
\text { Presentation }\end{array}$ & $\begin{array}{l}\text { Anatomic } \\
\text { Region }\end{array}$ & $\begin{array}{l}\text { No. of } \\
\text { Patients }\end{array}$ & $\begin{array}{c}\text { Prevalence } \\
\text { of DVT } \\
\%\end{array}$ & $\begin{array}{l}\text { Combined } \\
\text { Sensitivity } \\
\% \text { [95\% Cl] } \\
\text { or (range) }\end{array}$ & $\begin{array}{l}\text { Combined } \\
\text { Specificity } \\
\% \text { [95\% Cl] } \\
\text { or (range) }\end{array}$ \\
\hline White et al, ${ }^{50} 1989$ & Symptomatic & Thigh & 266 & 46 & 93 [88-97] & 98 [96-100] \\
\hline Becker et al, ${ }^{51} 1989$ & Symptomatic & Thigh and calf & 1,578 & 50 & $96(92-100)$ & $99(96-100)$ \\
\hline Cogo et al, ${ }^{52} 1995$ & Symptomatic & Thigh & 989 & 43 & 96 & 98 \\
\hline Wells et al, ${ }^{53} 1995$ & Asymptomatic & Thigh & 1,616 & 9 & 62 & 97 \\
\hline \multirow[t]{2}{*}{ Kearon et al, ${ }^{54} 1998$} & Symptomatic & Thigh & 2,763 & 40 & 89 [85-92] & 94 [90-98] \\
\hline & Asymptomatic & Thigh & 2,035 & 16 & 47 [37-57] & 94 [91-98] \\
\hline Gottlieb et al, ${ }^{55} 1999$ & Symptomatic & Calf & 212 & 25 & 93 [82-98] & 99 [96-99] \\
\hline Mustafa et al, ${ }^{56} 2002$ & Symptomatic & Upper extremity & 170 & 73 & $(56-100)$ & $(77-100)$ \\
\hline \multirow[t]{2}{*}{ Kassai et al, ${ }^{57} 2004$} & Asymptomatic & Thigh & 4,182 & NR & \multicolumn{2}{|c|}{$645^{*}[170-2,450]$} \\
\hline & & Calf & 2,324 & NR & \multicolumn{2}{|c|}{$35 *[12-105]$} \\
\hline
\end{tabular}

ity was maintained, but sensitivity was lower. Kearon et al reported a summary sensitivity of $47 \%{ }^{54}$ and Wells et al, of just $62 \% .{ }^{53}$ In contrast, one other review reported results as a diagnostic odds ratio, and implied an approximate sensitivity of at least $90 \% .{ }^{57}$

The single review focusing on calf vein thrombosis in symptomatic patients reported a summary sensitivity of $93 \%$ and specificity of $99 \% .{ }^{55}$ Subgroup analyses in other reviews, however, reported summary sensitivities of only $73 \%$ and $75 \% \cdot{ }^{52,54}$ For asymptomatic patients, the reported summary sensitivities for detecting calf vein thromboses were consistently around $50 \% .{ }^{53}$ The sensitivities and specificities of detecting thrombi in symptomatic upper extremities were generally low, ranging from $56 \%$ to $100 \%$ and $77 \%$ to $100 \%$, respectively. ${ }^{56}$

Based on these published systematic reviews, we conclude that ultrasonography has been found to have high sensitivity and specificity for diagnosing DVT of the proximal lower extremity. In high-risk asymptomatic patients, such as postoperative patients, specificity is maintained, but sensitivity may be substantially dimin-

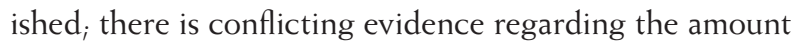
of diminution. For detecting calf vein thrombosis, the sensitivity was found to be poor. The clinical importance of isolated calf vein thrombosis was not addressed in these reviews. Because of the inconsistencies across reviews, we conclude there is level 2 evidence regarding use of ultrasonography for VTE diagnosis.

Importantly, the published literature addressed a radiological endpoint (presence of clot) rather than a clinical one. Evidence based on a clinical outcome may challenge the relevance of the apparently low sensitivity of ultrasonography for detecting thrombi in calf veins. A recent study has found a low rate $(0.8 \%)$ of symptomatic venous thromboembolism in patients who have anticoagulation withheld on the basis of a single negative ultrasound examination of both the proximal and distal veins. ${ }^{58}$

\section{Helical CT}

What are the test characteristics of belical CT for the diagnosis of pulmonary embolism?

We identified 10 systematic reviews summarizing the accuracy of helical CT for the diagnosis of pulmonary embolism, ${ }^{59-68}$ and excluded 1 study $^{59}$ for unclear study inclusion criteria (Table 4). ${ }^{60-68}$ All reported either sensitivity and specificity, or positive and negative likelihood ratios, as the primary indicators of $\mathrm{CT}$ performance, but they differed considerably in how the reference standard was defined. Four reviews included only studies in which conventional pulmonary arteriography was the reference standard, ${ }^{60,63,66,67}$ while the other reviews expanded the definition of a reference standard to include ventilation-perfusion scintigraphy ${ }^{64,65,68}$ or overall clinical assessment. ${ }^{61,62}$ Five reviews included only prospective studies. ${ }^{62-64,66,68}$ The description of search methods was generally the weakest element across systematic reviews (Supplemental Appendix 4, available online at http:// www.annfammed.org/cgi/content/full/5/1/63/ DC1). The 9 reviews included 33 primary studies, of which 8 studies were most consistently included across reviews. The newest reviews, ${ }^{59,66-68}$ published in 2005 and 2006, included studies published since 2000 which were not included in the earlier reviews. Only 1 review included the study by Winer-Muram, which used multidetector CT. ${ }^{69}$

The systematic reviews reported a wide range of summary sensitivities (66\%-93\%), with only 1 review reporting a summary sensitivity of greater than $90 \% .{ }^{61}$ 


\begin{tabular}{|c|c|c|c|c|c|}
\hline Author, Year & Main Inclusion Criteria & $\begin{array}{l}\text { No. of } \\
\text { Patients }\end{array}$ & $\begin{array}{l}\text { Prevalence } \\
\text { of Pulmonary } \\
\text { Embolism } \\
\%\end{array}$ & $\begin{array}{l}\text { Pooled } \\
\text { Sensitivity } \\
\% \text { (Range) } \\
\text { or }[95 \% \mathrm{Cl}]\end{array}$ & $\begin{array}{l}\text { Pooled } \\
\text { Specificity } \\
\% \text { (Range) } \\
\text { or [95\% Cl] }\end{array}$ \\
\hline Harvey et al, ${ }^{60} 2000$ & $\begin{array}{l}\text { Prospective and retrospective studies with } \\
\text { PA as reference standard in most cases }\end{array}$ & 813 & 34 & $79(47-100)$ & $89(75-100)$ \\
\hline Mullins et al, ${ }^{61} 2000$ & $\begin{array}{l}\text { Diagnosis established by PA or a clinical } \\
\text { reference standard* }\end{array}$ & 367 & 35 & $93(50-100)$ & $97(92-100)$ \\
\hline Rathbun et al, ${ }^{62} 2000$ & $\begin{array}{l}\text { Prospective studies evaluating use of CT } \\
\text { for diagnosis of PE using any reference } \\
\text { standard }\end{array}$ & 1,330 & NR & $(53-100)$ & $(81-100)$ \\
\hline Cueto et al, ${ }^{63} 2001$ & $\begin{array}{l}\text { Prospective studies with positive and } \\
\text { negative CT results; PA reference standard }\end{array}$ & 268 & NR & 80 [73-86] & 94 [91-98] \\
\hline van Beek et al, ${ }^{64} 2001$ & $\begin{array}{l}\text { Prospective studies reporting sensitivity and } \\
\text { specificity of CT relative to PA or V/Q scan }\end{array}$ & 1,171 & 39 & 88 [83-91] & 92 [89-94] \\
\hline Safriel \& Zinn, ${ }^{65} 2002$ & $\begin{array}{l}\text { Diagnosis established by PA or high- } \\
\text { probability V/Q scan }\end{array}$ & 1,250 & NR & 74 [57-100] & 90 [68-100] \\
\hline \multirow[t]{2}{*}{ Roy et al, ${ }^{66} 2005$} & Prospective studies; & 431 & NR & $24(12-47)^{\dagger}$ & \\
\hline & $\begin{array}{l}\text { consecutive patients; diagnosis established } \\
\text { by PA for confirmation strategies, and } \\
\text { PA or clinical follow-up for exclusion } \\
\text { strategies }\end{array}$ & 1,197 & NR & & $\begin{array}{l}0.11 \\
(0.06-0.19)^{\ddagger}\end{array}$ \\
\hline Hayashino et al, ${ }^{67} 2005$ & $\begin{array}{l}\text { Studies of helical CT compared to PA } \\
\text { obtained within } 48 \mathrm{hr}\end{array}$ & 520 & NR & $86(80-92)$ & $94(91-96)$ \\
\hline Hogg et al, ${ }^{68} 2006$ & $\begin{array}{l}\text { Prospective studies with } 85 \% \text { follow-up, } \\
\text { with adequate reference standard, or } \\
\text { clinical follow-up after negative CT }\end{array}$ & 749 & $19-79$ & $89(82-95)$ & $95(91-98)$ \\
\hline
\end{tabular}

The summary specificities had a narrower range (89\%-98\%).

We hypothesized that this apparent variability in CT accuracy was due to differences in the inclusion criteria of the systematic reviews. We therefore conducted our own systematic review including only prospective studies in which conventional pulmonary arteriography was uniformly applied as the reference standard for all participants. ${ }^{11}$ Because we required this reference standard, we identified only 9 studies that met these inclusion criteria (Table 5) 69-77 These studies reported data on 536 individuals and prevalences of pulmonary embolism ranging from $19 \%$ to $70 \%$. The studies were weakest in their description of the study population and description of how they addressed potential sources of bias. Despite our stringent inclusion criteria, our review also found a wide range of reported sensitivity (45\%-100\%) and specificity (78\%$100 \%)$. Only 4 of the 9 studies reported an overall sensitivity of greater than $90 \%$, whereas 6 of the 9 studies reported an overall specificity of greater than $90 \%$.

The published evidence therefore shows that, at best, helical CT should be considered about $90 \%$ sensitive for the detection of pulmonary emboli when compared with conventional pulmonary arteriography.
The specificity of CT appears to be somewhat higher, perhaps around 95\%.

This conclusion must be considered in the context of 3 caveats. First, practically all published evidence concerning the accuracy of CT in detecting pulmonary emboli is subject to substantial referral bias: participation required referral for either helical CT or the reference standard test. This bias could either inflate or deflate the apparent sensitivity and specificity of CT depending on the spectrum of cases that physicians refer for imaging. Second, the published literature has not kept up with advances in CT technology. Even though high-resolution multidetector CT scanners (4 or more detectors) are rapidly replacing single-detector models, only 1 primary study examined the accuracy of this new technology. ${ }^{69}$ This study, by Winer-Muram et al, reported a sensitivity of $100 \%$ for CT compared with conventional arteriography, providing evidence of the ability of multidetector scanners to detect smaller emboli compared with single-detector scanners.

Results were recently published from the PIOPED II study, evaluating multidetector CT. ${ }^{78}$ This study did not require all participants to undergo conventional pulmonary arteriography, so the design is not entirely comparable to the other studies we reviewed. None- 


\begin{tabular}{|c|c|c|c|c|c|c|c|}
\hline Author, Year & Main Inclusion Criteria & $\begin{array}{l}\text { No. of CT } \\
\text { Detectors }\end{array}$ & $\begin{array}{l}\text { No. of } \\
\text { Patients }\end{array}$ & $\begin{array}{l}\text { Most Distal } \\
\text { Arterial Level } \\
\text { Interpreted }\end{array}$ & $\begin{array}{c}\text { PE } \\
\text { Prevalence } \\
\%\end{array}$ & $\begin{array}{c}\text { Sensitivity } \\
\% \\
(95 \% \mathrm{Cl})\end{array}$ & $\begin{array}{c}\text { Specificity } \\
\% \\
(95 \% \text { Cl) }\end{array}$ \\
\hline $\begin{array}{l}\text { Remy-Jardin } \\
\text { et al, }{ }^{70} 1992\end{array}$ & $\begin{array}{l}\text { Clinically suspected PE or } \\
\text { unexplained chest } \\
\text { radiograph abnormality }\end{array}$ & 1 & 42 & Segmental & 43 & 100 [81-100] & 96 [79-100] \\
\hline $\begin{array}{l}\text { Blum et al, }{ }^{71} \\
1994\end{array}$ & $\begin{array}{l}\text { Clinical suspicion of } \\
\text { massive PE }\end{array}$ & 1 & 10 & Segmental & 70 & 100 [59-100] & $100[29-100]$ \\
\hline $\begin{array}{l}\text { Goodman } \\
\text { et al, }{ }^{72} 1995\end{array}$ & Nondiagnostic V/Q scan & 1 & 20 & Subsegmental & 55 & 64 [31-89] & 89 [52-100] \\
\hline $\begin{array}{l}\text { Remy-Jardin } \\
\text { et al, }{ }^{73} 1996\end{array}$ & $\begin{array}{l}\text { Referral for pulmonary } \\
\text { arteriography }\end{array}$ & 1 & 75 & Segmental & 57 & 91 [78-97] & 78 [60-91] \\
\hline $\begin{array}{l}\text { Christiansen, } \\
1997^{74}\end{array}$ & $\begin{array}{l}\text { High clinical suspicion } \\
\text { of } \mathrm{PE}\end{array}$ & 1 & 70 & Segmental & 27 & 89 [67-99] & 96 [87-100] \\
\hline $\begin{array}{l}\text { Drucker et al, }{ }^{75} \\
\quad 1998\end{array}$ & $\begin{array}{l}\text { Referral for pulmonary } \\
\text { arteriography }\end{array}$ & 1 & 47 & Segmental & 32 & $60[32-84]$ & 81 [64-93] \\
\hline $\begin{array}{l}\text { Qanadli et al, }{ }^{76} \\
2000\end{array}$ & $\begin{array}{l}\text { Referral to the radiology } \\
\text { department }\end{array}$ & 2 & 157 & Subsegmental & 39 & 90 [80-96] & 94 [87-98] \\
\hline $\begin{array}{l}\text { Velmahos } \\
\text { et al, }{ }^{77} 2001\end{array}$ & $\begin{array}{l}\text { Surgical ICU patients with } \\
\text { explicitly defined clinical } \\
\text { findings associated } \\
\text { with PE }\end{array}$ & 1 & 22 & Subsegmental & 50 & $45[17-77]$ & 82 [48-98] \\
\hline $\begin{array}{l}\text { Winer-Muram } \\
\text { et al, }{ }^{69} 2004 \\
\text { (multidetector } \\
\text { CT) }\end{array}$ & $\begin{array}{l}\text { Emergency department and } \\
\text { inpatients referred for } \\
\text { pulmonary arteriography }\end{array}$ & 4 & 93 & Subsegmental & 19 & $100[81-100]$ & 89 [80-95] \\
\hline
\end{tabular}

theless, this trial enrolled 1,090 patients with suspected pulmonary emboli. All patients had a clinical assessment and underwent CT angiography (with 4-row, 8 -row or 16 -row multidetector scanners) and venousphase imaging, as well as other testing modalities, to make a composite reference standard (venography, ultrasonography, ventilation-perfusion scanning, conventional arteriography). Of the enrolled participants, 824 had tests that could be evaluated, although 51 of these CTs yielded indeterminate results. Among patients with a clinical assessment of a high or intermediate probability of pulmonary embolism, the positive predictive values for multidetector CT angiography were $96 \%$ and 92\%, respectively. Among patients with a low clinical probability, the negative predictive value for multidetector CT angiography was $96 \%$.

Given the inconsistencies in the primary literature and the few published studies with multidetector scanners and a definitive reference standard, we conclude that the evidence on this question is level 2 .

Of note, studies have reported low rates of thromboembolic events in patients with suspected pulmonary embolism in whom the CT examination was negative or indeterminate and anticoagulation was withheld, suggesting that detection of emboli in distal, subsegmental pulmonary vessels may have little clinical importance. ${ }^{79,80}$ In 1 systematic review, the 3 -month event rate was estimated to be only $1.4 \%{ }^{81}$
In another, which included some studies with longer follow-up, the rate was similarly low. ${ }^{80}$ While these findings imply that CT has a high negative predictive value, it cannot be attributed solely to the performance of CT because, in nearly all studies in this review, 1 or more additional diagnostic tests were concomitantly performed. The decision to withhold anticoagulation was made using the results of all tests, including results from helical CT. A recent systematic review also nicely demonstrated the value of combined modalities. ${ }^{82}$ The authors reviewed 25 studies involving more than 7,000 patients. They found the literature supports that 2 strategies were highly effective in excluding pulmonary embolism; (1) normal results on pulmonary angiography or lung scintigraphy, and (2) normal Ddimer levels combined with low clinical probability. In patients in whom the first round of testing was inconclusive, such as those with a nondiagnostic lung scan, both pulmonary angiography and serial leg testing for venous thrombosis were accurate and safe. When D-dimer testing combined with clinical probability was inconclusive, a normal perfusion lung scan safely excluded pulmonary embolism.

The evidence strongly supports the use of clinical prediction rules for establishing the pretest probability of DVT or pulmonary embolism in a patient before more definitive testing. The pretest probability can then be used in interpreting the subsequent test 
results. The use of a D-dimer assay with a clinical prediction rule may even have a negative predictive value high enough to obviate the need for imaging studies in many patients. The evidence regarding the use of $\mathrm{D}$-dimer, in isolation, is also strong in that it high negative predictive values for some D-dimer assays (ELISA and quantitative rapid ELISA) were found in appropriately chosen patients_primarily nonelderly outpatients having a short duration of symptoms. The test characteristics of ultrasonography for diagnosis of DVT vary depending on the veins of interest- the evidence supports that ultrasonography is a good testing modality for diagnosing proximal vein thrombosis in symptomatic patients, but it is less accurate in distal veins, upper extremity veins, and in asymptomatic patients. Use of CT for diagnosis of pulmonary embolism is an evolving field. Multidetector scanners are becoming the norm in many hospitals but the test characteristics for diagnosing pulmonary embolism using these scanners is, as of yet, minimally characterized. The sensitivity of single-detector helical scanners varied widely across studies although the clinical importance of missing subsegmental clot is not clear.

Future research should include additional published studies on the test characteristics of multidetector CT scans and systematic reviews of the use of combined modalities or algorithms for diagnosing DVT and pulmonary embolism. The field would be advanced by systematic reviews consolidating information from the many published algorithms reporting sensitivities and specificities relative to an established reference standard, as well as the algorithms that use clinical outcomes during follow-up as the reference standard.

To read or post commentaries in response to this article, see it online at http://www.annfammed.org/cgi/current/full/5/1/63.

Submitted May 31, 2006; submitted revised September 18, 2006; accepted September 28, 2006.

Key words: Venous thromboembolism/diagnosis review, systematic; D-dimer; computed tomography scanners; deep venous thrombosis/ diagnosis; pulmonary embolism/diagnosis; ultrasonography; prediction rules; forecasting; practice guidelines

Funding support: Portions of this work were completed by the Johns Hopkins Evidence-Based Practice Center under Contract to the Agency for Healthcare Research and Quality (contract no. 290-97-0006), Rockville, Md. The authors are responsible for the content of this article, including any treatment recommendations. No statement in this article should be construed as an official position of the Agency for Healthcare Research and Quality or of the US Department of Health and Human Services.

\section{References}

1. Heit JA, Melton LJ 3rd, Lohse CM, et al. Incidence of venous thromboembolism in hospitalized patients vs community residents. Mayo Clin Proc. 2001;76(11):1102-1110.
2. White RH. The epidemiology of venous thromboembolism. Circulation. 2003;107(23 Suppl 1):14-8.

3. Fowkes FJ, Price JF, Fowkes FG. Incidence of diagnosed deep vein thrombosis in the general population: systematic review. Eur J Vasc Endovasc Surg. 2003(1);25:1-5.

4. Anderson FA, Jr., Wheeler HB, Goldberg RJ, et al. A populationbased perspective of the hospital incidence and case-fatality rates of deep vein thrombosis and pulmonary embolism. The Worcester DVT Study. Arch Intern Med. 1991;151(5):933-938.

5. Moser KM, Fedullo PF, LitteJohn JK, Crawford R. Frequent asymptomatic pulmonary embolism in patients with deep venous thrombosis. JAMA. 1994;271(3):223-225.

6. Heit JA, Silverstein MD, Mohr DN, et al. Predictors of survival after deep vein thrombosis and pulmonary embolism: a populationbased, cohort study. Arch Intern Med. 1999;159(5):445-453.

7. Streiff MB, Segal JB, Tamariz LJ, et al. Duration of vitamin K antagonist therapy for venous thromboembolism: a systematic review of the literature. Am J Hematol. 2006;81(9):684-691.

8. Hull RD, Raskob GE, Brant RF, Pineo GF, Valentine KA. Relation between the time to achieve the lower limit of the APTT therapeutic range and recurrent venous thromboembolism during heparin treatment for deep vein thrombosis. Arch Intern Med. 1997;157(22):2562-2568.

9. Segal JB, Eng J, Jenckes MW, et al. Diagnosis and treatment of deep venous thrombosis and pulmonary embolism. Evid Rep Technol Assess (Summ). 2003(68):1-6.

10. Qaseem A, Snow V, Barry P, et al, for the Joint AAFP/ACP Panel on DVT/PE. Current Diagnosis of Venous Thromboembolism in Primary Care: A clinical practice guideline from the American Academy of Family Physicians and the American College of Physicians. Ann Fam Med. 2007;5(1):57-62.

11. Eng J, Krishnan JA, Segal JB, et al. Accuracy of CT in the diagnosis of pulmonary embolism: a systematic literature review. AJR Am J Roentgenol. 2004;183(6):1819-1827.

12. Tamariz LJ, Eng J, Segal JB, et al. Usefulness of clinical prediction rules for the diagnosis of venous thromboembolism: a systematic review. Am J Med. 2004;117(9):676-684.

13. Segal J, Eng J, Jenckes M, et al. Diagnosis and Treatment of Deep Venous Thrombosis and Pulmonary Embolism. Evidence Report/ Technology Assessment. Rockville, MD: Prepared by the Johns Hopkins Evidence-based Practice Center under Contract No. 29097-0007; 2003. AHRQ Publication No. 03-E016.

14. Metz CE. Some practical issues of experimental design and data analysis in radiological ROC studies. Invest Radiol. 1989;24(3): 234-245.

15. Ebell MH, Siwek J, Weiss BD, et al. Strength of recommendation taxonomy (SORT): a patient-centered approach to grading evidence in the medical literature. Am Fam Physician. 2004;69(3):548-556.

16. Anderson DR, Wells PS, Stiell I, et al. Thrombosis in the emergency department: use of a clinical diagnosis model to safely avoid the need for urgent radiological investigation. Arch Intern Med. 1999;159(5):477-482.

17. Kraaijenhagen RA, Piovella F, Bernardi E, et al. Simplification of the diagnostic management of suspected deep vein thrombosis. Arch Intern Med. 2002;162(8):907-911.

18. Wells PS, Anderson DR, Bormanis J, et al. Value of assessment of pretest probability of deep-vein thrombosis in clinical management. Lancet. 1997;350(9094):1795-1798.

19. Cornuz J, Ghali WA, Hayoz D, et al. Clinical prediction of deep venous thrombosis using two risk assessment methods in combination with rapid quantitative D-dimer testing. Am J Med. 2002;112(3):198-203.

20. Wells PS, Hirsh J, Anderson DR, et al. Accuracy of clinical assessment of deep-vein thrombosis. Lancet. 1995;345(8961):1326-1330. 
21. Dryjski M, O'Brien-Irr MS, Harris LM, Hassett J, Janicke D. Evaluation of a screening protocol to exclude the diagnosis of deep venous thrombosis among emergency department patients. J Vasc Surg. 2001;34(6):1010-1015.

22. Anderson DR, Wells PS, Stiell I, et al. Management of patients with suspected deep vein thrombosis in the emergency department: combining use of a clinical diagnosis model with D-dimer testing. J Emerg Med. 2000;19(3):225-230.

23. Funfsinn N, Caliezi C, Biasiutti FD, et al. Rapid D-dimer testing and pre-test clinical probability in the exclusion of deep venous thrombosis in symptomatic outpatients. Blood Coagul Fibrinolysis. 2001;12(3):165-170.

24. Constans J, Nelzy ML, Salmi LR, et al. Clinical prediction of lower limb deep vein thrombosis in symptomatic hospitalized patients. Thromb Haemost. 2001;86(4):985-990.

25. Kearon C, Ginsberg JS, Douketis J, et al. Management of suspected deep venous thrombosis in outpatients by using clinical assessment and D-dimer testing. Ann Intern Med. 2001;135(2):108-111.

26. Aschwanden M, Labs KH, Jeanneret C, Gehrig A, Jaeger KA. The value of rapid $\mathrm{D}$-dimer testing combined with structured clinical evaluation for the diagnosis of deep vein thrombosis. J Vasc Surg. 1999;30(5):929-935.

27. Nypaver TJ, Shepard AD, Kiell CS, et al. Outpatient duplex scanning for deep vein thrombosis: parameters predictive of a negative study result. J Vasc Surg. 1993;18(5):821-826.

28. Lennox AF, Delis KT, Serunkuma $S$, et al. Combination of a clinical risk assessment score and rapid whole blood D-dimer testing in the diagnosis of deep vein thrombosis in symptomatic patients. J Vasc Surg. 1999;30(5):794-803.

29. Schutgens RE, Ackermark P, Haas FJ, et al. Combination of a normal D-dimer concentration and a non-high pretest clinical probability score is a safe strategy to exclude deep venous thrombosis. Circulation. 2003;107(4):593-597.

30. Shields GP, Turnipseed S, Panacek EA, et al. Validation of the Canadian clinical probability model for acute venous thrombosis. Acad Emerg Med. 2002;9(6):561-566

31. Ruiz-Gimenez N, Friera A, Artieda P, et al. Rapid D-dimer test combined a clinical model for deep vein thrombosis. Validation with ultrasonography and clinical follow-up in 383 patients. Thromb Haemost. 2004;91(6):1237-1246.

32. Ilkhanipour $\mathrm{K}$, Wolfson $A B$, Walker $H$, et al. Combining clinical risk with $\mathrm{D}$-dimer testing to rule out deep vein thrombosis. J Emerg Med. 2004;27(3):233-239.

33. Wells PS, Anderson DR, Bormanis J, et al. Application of a diagnostic clinical model for the management of hospitalized patients with suspected deep-vein thrombosis. Thromb Haemost. 1999;81(4):493-497.

34. Tick LW, Ton E, van Voorthuizen T, et al. Practical diagnostic management of patients with clinically suspected deep vein thrombosis by clinical probability test, compression ultrasonography, and Ddimer test. Am J Med. 2002;113(8):630-635.

35. Wells PS, Ginsberg JS, Anderson DR, et al. Use of a clinical model for safe management of patients with suspected pulmonary embolism. Ann Intern Med. 1998;129(12):997-1005.

36. Sanson BJ, Lijmer JG, Mac Gillavry MR, et al. Comparison of a clinical probability estimate and two clinical models in patients with suspected pulmonary embolism. ANTELOPE-Study Group. Thromb Haemost. 2000;83(2):199-203.

37. Wells PS, Anderson DR, Rodger M, et al. Derivation of a simple clinical model to categorize patients probability of pulmonary embolism: increasing the models utility with the SimpliRED Ddimer. Thromb Haemost. 2000;83(3):416-420.

38. Wells PS, Anderson DR, Rodger M, et al. Excluding pulmonary embolism at the bedside without diagnostic imaging: management of patients with suspected pulmonary embolism presenting to the emergency department by using a simple clinical model and ddimer. Ann Intern Med. 2001;135(2):98-107.
39. Stollberger C, Finsterer J, Lutz W, et al. Multivariate analysisbased prediction rule for pulmonary embolism. Thromb Res. 2000;97(5):267-273.

40. Chagnon I, Bounameaux H, Aujesky D, et al. Comparison of two clinical prediction rules and implicit assessment among patients with suspected pulmonary embolism. Am J Med. 2002;113(4):269-275.

41. Perrier A, Roy PM, Aujesky D, et al. Diagnosing pulmonary embolism in outpatients with clinical assessment, D-dimer measurement, venous ultrasound, and helical computed tomography: a multicenter management study. Am J Med. 2004;116(5):291-299.

42. Righini M, Aujesky D, Roy PM, et al. Clinical usefulness of Ddimer depending on clinical probability and cutoff value in outpatients with suspected pulmonary embolism. Arch Intern Med. 2004;164(22):2483-2487.

43. Fancher TL, White RH, Kravitz RL. Combined use of rapid D-dimer testing and estimation of clinical probability in the diagnosis of deep vein thrombosis: systematic review. BMJ. 2004(7470);329:821

44. Becker DM, Philbrick JT, Bachhuber TL, Humphries JE. D-dimer testing and acute venous thromboembolism. A shortcut to accurate diagnosis? Arch Intern Med. 1996;156(9):939-946.

45. Brown MD, Lau J, Nelson RD, Kline JA. Turbidimetric D-dimer test in the diagnosis of pulmonary embolism: a metaanalysis. Clin Chem. 2003:49(11):1846-1853

46. Brown MD, Rowe BH, Reeves MJ, Bermingham JM, Goldhaber SZ. The accuracy of the enzyme-linked immunosorbent assay D-dimer test in the diagnosis of pulmonary embolism: a meta-analysis. Ann Emerg Med. 2002;40(2):133-144.

47. Heim SW, Schectman JM, Siadaty MS, Philbrick JT. D-dimer testing for deep venous thrombosis: a metaanalysis. Clin Chem. 2004;50(7):1136-1147.

48. Stein PD, Hull RD, Patel KC, et al. D-dimer for the exclusion of acute venous thrombosis and pulmonary embolism: a systematic review. Ann Intern Med. 2004;140(8):589-602.

49. Kraaijenhagen RA, Lensing AW, Lijmer JG, et al. Diagnostic strategies for the management of patients with clinically suspected deepvein thrombosis. Curr Opin Pulm Med. 1997;3(4):268-274.

50. White RH, McGahan JP, Daschbach MM, Hartling RP. Diagnosis of deep-vein thrombosis using duplex ultrasound. Ann Intern Med. 1989;111:297-304

51. Becker DM, Philbrick JT, Abbitt PL. Real-time ultrasonography for the diagnosis of lower extremity deep venous thrombosis. The wave of the future? Arch Intern Med. 1989;149(8):1731-1734.

52. Cogo A, Lensing AW, Wells P, Prandoni P, Buller HR. Noninvasive objective tests for the diagnosis of clinically suspected deep-vein thrombosis. Haemostasis. 1995;25(1-2):27-39.

53. Wells PS, Lensing AW, Davidson BL, Prins MH, Hirsh J. Accuracy of ultrasound for the diagnosis of deep venous thrombosis in asymptomatic patients after orthopedic surgery. A meta-analysis. Ann Intern Med. 1995;122(1):47-53.

54. Kearon C, Julian JA, Newman TE, Ginsberg JS. Noninvasive diagnosis of deep venous thrombosis. McMaster Diagnostic Imaging Practice Guidelines Initiative. Ann Intern Med. 1998;128(8):663-677.

55. Gottlieb RH, Widjaja J, Tian L, Rubens DJ, Voci SL. Calf sonography for detecting deep venous thrombosis in symptomatic patients: experience and review of the literature. J Clin Ultrasound. 1999;27(8):415-420.

56. Mustafa BO, Rathbun SW, Whitsett TL, Raskob GE. Sensitivity and specificity of ultrasonography in the diagnosis of upper extrem ity deep vein thrombosis: a systematic review. Arch Intern Med. 2002;162(4):401-404.

57. Kassai B, Boissel JP, Cucherat M, et al. A systematic review of the accuracy of ultrasound in the diagnosis of deep venous thrombosis in asymptomatic patients. Thromb Haemost. 2004;91(4):655-666. 
58. Stevens SM, Elliott CG, Chan KJ, Egger MJ, Ahmed KM. Withholding anticoagulation after a negative result on duplex ultrasonography for suspected symptomatic deep venous thrombosis. Ann Intern Med. 2004;140(12):985-991.

59. Russo V, Piva T, Lovato L, Fattori R, Gavelli G. Multidetector CT: a new gold standard in the diagnosis of pulmonary embolism? State of the art and diagnostic algorithms. Radiol Med (Torino). 2005;109(1-2):49-61; quiz 62-43.

60. Harvey RT, Gefter WB, Hrung JM, Langlotz CP. Accuracy of CT angiography versus pulmonary angiography in the diagnosis of acute pulmonary embolism: evaluation of the literature with summary ROC curve analysis. Acad Radiol. 2000;7(10):786-797.

61. Mullins MD, Becker DM, Hagspiel KD, Philbrick JT. The role of spiral volumetric computed tomography in the diagnosis of pulmonary embolism. Arch Intern Med. 2000;160(3):293-298.

62. Rathbun SW, Raskob GE, Whitsett TL. Sensitivity and specificity of helical computed tomography in the diagnosis of pulmonary embo lism: a systematic review. Ann Intern Med. 2000;132(3):227-232.

63. Cueto SM, Cavanaugh SH, Benenson RS, Redclift MS. Computed tomography scan versus ventilation-perfusion lung scan in the detection of pulmonary embolism. J Emerg Med. 2001;21(2):155-164.

64. van Beek EJ, Brouwers EM, Song B, Bongaerts AH, Oudkerk M. Lung scintigraphy and helical computed tomography for the diagnosis of pulmonary embolism: a meta-analysis. Clin Appl Thromb Hemost. 2001;7(2):87-92.

65. Safriel Y, Zinn H. CT pulmonary angiography in the detection of pulmonary emboli: a meta-analysis of sensitivities and specificities. Clin Imaging. 2002;26(2):101-105.

66. Roy PM, Colombet I, Durieux P, et al. Systematic review and metaanalysis of strategies for the diagnosis of suspected pulmonary embolism. BMJ. 2005;331(7511):259.

67. Hayashino Y, Goto M, Noguchi Y, Fukui T. Ventilation-perfusion scanning and helical CT in suspected pulmonary embolism: metaanalysis of diagnostic performance. Radiology. 2005;234(3):740-748.

68. Hogg K, Brown G, Dunning J, et al. Diagnosis of pulmonary embolism with CT pulmonary angiography: a systematic review. Emerg Med J. 2006;23(3):172-178.

69. Winer-Muram HT, Rydberg J, Johnson MS, et al. Suspected acute pulmonary embolism: evaluation with multi-detector row CT versus digital subtraction pulmonary arteriography. Radiology. 2004;233(3):806-815.

70. Remy-Jardin M, Remy J, Wattinne L, Giraud F. Central pulmonary thromboembolism: diagnosis with spiral volumetric CT with the single-breath-hold technique--comparison with pulmonary angiography. Radiology. 1992;185(2):381-387.
71. Blum AG, Delfau F, Grignon B, et al. Spiral-computed tomography versus pulmonary angiography in the diagnosis of acute massive pulmonary embolism. Am J Cardiol. 1994;74(1):96-98.

72. Goodman LR, Curtin JJ, Mewissen MW, et al. Detection of pulmonary embolism in patients with unresolved clinical and scintigraphic diagnosis: helical CT versus angiography. AJR Am J Roentgenol. 1995;164(6):1369-1374.

73. Remy-Jardin M, Remy J, Deschildre F, et al. Diagnosis of pulmonary embolism with spiral CT: comparison with pulmonary angiography and scintigraphy. Radiology. 1996;200(3):699-706.

74. Christiansen F. Diagnostic imaging of acute pulmonary embolism. Acta Radiol Suppl. 1997;410:1-33.

75. Drucker EA, Rivitz SM, Shepard JA, et al. Acute pulmonary embolism: assessment of helical CT for diagnosis. Radiology. 1998;209(1):235-241

76. Qanadli SD, Hajjam ME, Mesurolle B, et al. Pulmonary embolism detection: prospective evaluation of dual-section helical CT versus selective pulmonary arteriography in 157 patients. Radiology. 2000;217(2):447-455

77. Velmahos GC, Vassiliu P, Wilcox A, et al. Spiral computed tomography for the diagnosis of pulmonary embolism in critically ill surgical patients: a comparison with pulmonary angiography. Arch Surg. 2001;136(5):505-511.

78. Stein PD, Fowler SE, Goodman LR, et al. Multidetector computed tomography for acute pulmonary embolism. $N$ Engl J Med. 2006;354(22):2317-2327.

79. Eyer BA, Goodman LR, Washington L. Clinicians' response to radiologists' reports of isolated subsegmental pulmonary embolism or inconclusive interpretation of pulmonary embolism using MDCT. AJR Am J Roentgenol. 2005;184(2):623-628.

80. Quiroz R, Kucher N, Zou KH, et al. Clinical validity of a negative computed tomography scan in patients with suspected pulmonary embolism: a systematic review. JAMA. 2005;293(16):2012-2017.

81. Moores LK, Jackson WL, Jr., Shorr AF, Jackson JL. Meta-analysis: outcomes in patients with suspected pulmonary embolism managed with computed tomographic pulmonary angiography. Ann Intern Med. 2004;141(11):866-874.

82. Kruip MJ, Leclercq MG, van der Heul C, Prins MH, Buller HR Diagnostic strategies for excluding pulmonary embolism in clinical outcome studies. A systematic review. Ann Intern Med. 2003;138(12):941-951. 